\title{
Turkish Validity and Reliability of Physical Education and Sport Course Exam Anxiety Scale
}

\section{Beden Eğitimi ve Spor Dersi Sınav Kaygısı Ölçeğinin Türkçe Geçerlik ve Güvenirliği}

\section{Erhan Devrilmez}

Faculty of Sport Sciences, Karamanoğlu Mehmetbey University

https://orcid.org/0000-0002-5136-7510

Dilem Çiy ${ }^{1}$

Faculty of Sport Sciences, Karamanoğlu Mehmetbey University

https://orcid.org/0000-0001-6283-4033

Mert Bilgiç

Faculty of Sport Sciences, Akdeniz University,

https://orcid.org/00o0-0001-6883-3269

Fatih Dervent

Faculty of Sport Sciences, Marmara University

https://orcid.org/0000-0002-2612-3549

Received: February 19, 2021

Accepted: March 28, 2021

Online Published: April 3, 2021

DOI: 10.30655/besad.2021.31

https//doi.org/10.30655/besad.2021.31

\begin{abstract}
ÖZ
Öğrenme sürecinin sonunda bir sınıf atlamanın veya bir derece elde etmenin belirleyicisi olan sınavlar, öğrenciler için genel anlamda kaygı unsuru olabilir. Bu durum beden eğitimi ve spor dersleri için de geçerlidir ve ölçülmesi önemlidir. Bu çalışmanın amacı, Danthony, Mascret ve Cury (2019) tarafından geliştirilen Beden Eğitimi ve Spor Dersi Sınav Kaygısı Ölçeğinin Türk kültürüne uyarlamasının gerçekleştirilmesidir. Ölçeğin uyarlama süreci iki dil uzmanı tarafından gerçekleştirilmiştir. Çalışmaya 195 kız ve 164 erkek toplam 359 ortaokul öğrencisi gönüllü olarak katılmıştır. Rastgele yöntemle 74 katılımcı açımlayıcı faktör analizi, 200 öğrenci doğrulayıcı faktör analizi ve 85 öğrenci ise test tekrar test analizi için ayrılmıştır. Çalışma verisi 2019-2020 güz döneminde toplanmıştır. Beden eğitimi ve spor dersi sınav kaygıı ölçeğinin geçerliği için açımlayıcı ve doğrulayıcı faktör analizleri kullanılmıştır. Ölçeğin güvenirliği için ise Cronbach Alfa iç tutarlıık ve test tekrar test analizleri kullanılmıştır. Açımlayıcı faktör analizi bulguları, ölçeğin orijinal halinde yer aldığı gibi 19 madde ve beş faktörlü yapıyı belirlemiştir. Belirlenen yapı, toplam varyansın \% 67.18'ini açıklamaktadır. Doğrulayıcı faktör analizi bulguları, modelin uyum indekslerinin ve parametrelerinin tamamının beklenen düzeyin üzerinde olduğunu göstermektedir. Güvenirlik analizlerinden iç tutarlıık Cronbach Alfa katsayısı toplam ölçek için .81 ile yeterli bulunmuştur. Ayrıca ölçeğin alt boyutlarının değerleri endişe .68, kendin kendine odaklanma .77, bedensel belirtiler .75, fiziksel gerginlik .86 ve algılanan kontrol .89 olarak belirlenmiştir. Ölçeğin test tekrar test güvenirliği için toplam değer .88 olarak tespit edilmiştir Ölçeğin test tekrar test güvenirliği alt boyutlar açısından incelendiğinde endişe .81, kendin kendine odaklanma .84,
\end{abstract}

\footnotetext{
${ }^{1}$ Corresponding Author: Dilem Çiy

dilem.ciy@hotmail.com

Karamanoğlu Mehmetbey Üniversitesi, Spor Bilimleri Fakültesi, Karaman, Turkey
} 
bedensel belirtiler .82, fiziksel gerginlik .86 ve algılanan kontrol .79 olarak bulunmuştur. Bu değerler ölçeğin toplam ve alt boyutlarının güvenilir olduğunu göstermektedir. Sonuç olarak, Türk kültürüne uyarlaması yapılan ölçek, öğrencilerin beden eğitimi ve spor dersi sınav kaygılarını ölçmek için geçerli ve güvenilir bir ölçme aracıdır.

Anahtar Kelimeler: Faktör analizi, ölçek uyarlama, ortaokul öğrencileri

\begin{abstract}
Exams, which are the determination of passing-failing grading or graduating at the end of the learning process, can be an anxiety concern for students. This situation is similar in physical education and sport courses and measuring this exam anxiety level seems important. The purpose of this study was to adapt the physical education and sport course exam anxiety scale developed by Danthony, Mascret and Cury (2019) to Turkish context. Adaptation process of the scale was executed by two language experts. Participants were 195 girls and 164 boys, totally 359 middle school students.All participants voluntarily accepted to attend this study. With the random method, 74 participants were allocated for exploratory factor analysis, 200 of them for confirmatory factor analysis and 85 of them for test-retest analysis. Data were collected from the 2019-2020 education year fall semester. Exploratory and confirmatory factor analyses were used for checking validity of the scale. To measure reliability of the scale, cronbach alpha internal consistency and test-retest methods were conducted. Results of exploratory factor analysis showed that the structure of the scale consisted of 19 items and five factors. This structure explained $67.18 \%$ of total variance. Results of confirmatory factor analysis indicated that all fit indexes and parameters of the scale were higher than expected level. Cronbach alpha coefficient results of factors were determined as worry .68, self-focus .77, bodily symptoms.75, somatic tension .86, perceived control .89. Cronbach Alpha coefficient for total scale was.81. Total and factors values of the scale indicated that scale is a reliable tool. As a conclusion, scale adapted Turkish context was valid and reliable in order to measure students' physical education and sport course exam anxiety level.
\end{abstract}

Key Words: Factor analysis, scale adaptation, middle school students

\title{
Giriş
}

Kişiler günlük yaşamlarında sınav, ameliyat, yarışma gibibir çok farklı durumlarla karşılaşabilir. Bu tarz durumlarda korku ve tedirginlik hissetmeleri doğaldır. Hissedilen bu duygular kişilerin yaşamını zorlaştırmaya, uyku düzenlerini bozmaya ve gereken hayat rutini uygulamalarını sekteye uğratmaya başladığında kaygı ortaya çıkabilir (Özgür, 2018). Kaygı, herhangi bir sebep oluşmamışken kişinin bu sebebe bağlı bir durum oluşacakmış gibi hissetmesine yol açan ve sonuçta tedirginlik hissi yaratan bir durumdur (Cüceloğlu, 1994; Yavuzer, 2004). Alanyazında kaygı, durumluk ve sürekli kaygı olmak üzere ikiye ayrılmaktadır. Durumluk kaygı, kişinin kendini tehlikede hissettiği durumlarda strese bağlı olarak kaygı düzeyinde artış olması ve stres durumunun ortadan kalkması ile birlikte hissedilen kaygı durumunun sona ermesi olarak tanımlanmaktadır (Öner \& Le Compte, 1983). Sürekli kaygı ise kişinin herhangi bir sorun ya da olay olmaksızın genel olarak kaygı hissetmesi durumu olarak ifade edilmektedir (Coşkun \& Akkaş, 2009). Sürekli kaygı kişi kendini daima kötü bir şeyle karşı karşıya kalacakmış gibi hisseder ve huzursuzluk duyar. Bu iki kaygı türü de okullarda yapılan sınavlarda görülebilmektedir.

Öğrenciler, eğitim öğretim hayatları boyunca sıklıkla sınavlarla, çeşitli ölçme ve değerlendirme unsurlarıyla karşı karşıya kalmaktadırlar. Sınavlar uygulanan eğitim ve öğretim programı kapsamında öğrencilerin akademik durumunu göstermesinin yanı sıra tehdit edici, kaygı ve endişe uyandırıcı olabilir (Putwain vd.. 2010). Beden eğitimi açısından da durum diğer derslerden farksızdır (Danthony vd., 2020).

Sınavların ve diğer değerlendirme süreçlerinin tehdit edici bir şekilde algılanması sınav kaygısına sebep olmaktadır (Spielberger ve Vagg, 1995). Diğer bir ifadeyle sınav kaygısı, değerlendirmenin sebep olduğu bir kaygı türüdür (Zeidner ve Matthews, 2005). Alanyazında sınav kaygısı üzerine yapılan çalışmalar çoğunlukla sınav kaygısının standardize edilmiş bilişsel testlerdeki akademik başarı üzerindeki etkisi gibi bilişsel yeterlikler üzerine yoğunlaşmıştır. Pek çok çalışmada yüksek sınav kaygısı ile başarı arasında negatif ilişkisi ortaya konulmuştur (Chapell vd., 2005; Putwain vd., 2010; Zeidner, 1998). Türkiye'de sınav kaygısı ile ilgili yapılan çalışmalar öğrencilerin yüksek düzeyde sınav kaygısı yaşadığını ortaya koymaktadır (Gençdoğan, 2006; Gündoğdu, 1994). 
Öğrenme sürecinin sonunda bir sınıf atlamanın veya bir derece elde etmenin belirleyicisi olan sınavlar, öğrenciler için genel anlamda kaygı unsuru olabilir. Bu kaygı ve endişeyi oluşturan faktörlerden bazıları değer bağlamındaki tehditler, diğer insanlardan gelebilecek olumsuz değerlendirmeler, başarısızlık korkusu ve aile baskısıdır (Putwain vd., 2010; Zeidner, 2007). Beden eğitimi ve spor dersi sınavlarında da öğrenciler benzer tehdit edici faktörler ile karşılaştıkları gözlenmektedir. Belirtilenlerin haricinde, beden eğitimi ve spor dersi sınavlarında ortaya çıkan sınav kaygısı faktörlerinden biri de sınav performansının çoğunlukla doğrudan öğretmenin ve diğer öğrencilerin önünde gerçekleşmesidir (Barkoukis vd., 2012). Örneğin, Danthony ve arkadaşları (2019) beden eğitimi ve spor dersinde bir hareket serisinin sınıf önünde sergilenmesi sınav kaygısına sebep olmazken aynı serinin öğrenme sürecinin sonunda bir nota karşıık gelecek şekilde sınıf önünde sergilenmesi sınav kaygısına yol açabileceğini belirtmektedirler. Beden eğitimi ve spor derslerinden düşük not almak ve/veya sınavda başarısız olmak beden eğitiminin fiziksel beceri yeterliği ile ilişkisi göz önüne alındığında bir diğer kaygı unsuru olarak görülebilir. Fiziksel olarak aktif olmanın sosyal açıdan olumlu bir olgu olduğu da düşünüldügünde; beden eğitimi ve spor dersi özelinde sınav kaygısı çalışmalarının gerekli olduğu düşünülmektedir. Bu çalışmanın önemi, genel eğitim alanyazınında kapsamlı sınav kaygısı çalışmaları olmasına rağmen beden eğitimi alanyazında yeterli çalışma bulunmamasıdır (Danthony vd., 2019).

Beden eğitimi ve spor, hem spor hem de eğitsel öğeleri birleştiren bir derstir. Beden eğitimi ve spor bir yandan temel hareket becerilerini geliştirmeye çalışırken (fiziksel aktivite ve sportif etkinlikler) bir yandan da öğrencilerin eğitsel becerileri edinmesi üzerine (işbirliği, adil oyun, sorumluluk, problem çözme, vb.) çalışmaktadır. Bu da öğrencilerin okul dışında da fiziksel olarak aktif olmaları ve öz-saygılarını arttırmaları noktasında olumlu duyuşsal tecrübeler edinmesini sağlamaktadır (Walling \& Duda, 1995). Beden eğitimi ve spor dersinde sınav kaygısı, öğrenme sürecinin sonundaki sınavda puanlanan bir performansa ilişkin algılanan tehdidin sebep olduğu reaksiyon ve olumsuz duygu durumu olarak düşünülebilir.

Alanyazında var olan sınav kaygısı ölçme araçları (Benson \& El-Zahhar, 1994; Spielberger, 1980) dersin kendine özgü yapısını gözetmeksizin genel olarak sınav kaygısını değerlendirmek için kullanılmaktadır. Beden eğitimi ve spor dersi diğer derslere kıyasla pek çok öğrenci tarafından eğlenceli bir ders olarak görülmektedir. Diğer taraftan bazı öğrenciler için beden eğitimi ve spor dersine katılımı stresli bir süreç olabilir (Barkoukis vd., 2005). Beden eğitimi ve spor derslerindeki kaygı çeşitli çalışmalarda incelenmiş olmasına rağmen beden eğitimi ve spor dersi sınav kaygısı özel olarak incelenmemiştir. Bunun en temel sebeplerinden biri alanyazında beden eğitiminde durumluk ve süreklik kaygıyı değerlendiren çeşitli ölçme araçlarının geliştirilmiş olmasına rağmen (Barkoukis vd., 2005: Spielberger, 1980) beden eğitimi ve spor dersi sınav kaygısı bağlamında geliştirilen bir ölçme aracının eksikliğidir. Son zamanlarda bu eksikliği ortadan kaldırmak amacıyla bazı çalışmalar gerçekleştirilmiştir (Danthony vd., 2019).

Beden eğitimi ve spor dersi sınavlarındaki kaygı, Danthony ve arkadaşları tarafından 2019 yılında geliştirilen Beden Eğitimi Dersi Sınav Kaygısı Ölçeği (RTA + Regulatory - Physical Education Scale - RTAR-PE) ile değerlendirilmiştir. RTAR-PE revize edilmiş sınav kaygısı ölçeği, beden eğitimi ve spor özeline uyarlanmıştır. Ölçekte 19 madde ve beş boyut bulunmaktadır: (i) Endişe (örn. Başarısızlık korkusu); (ii) Kendi kendine odaklanma (Sınavlarda diğerlerinin kişinin kendi performansına dair ne düşünebileceği veya söyleyebileceği); (iii) Bedensel belirtiler (Artan kalp atım hızı, ağız kuruması, nefes alıp vermede zorlanma); (iv) Fiziksel gerginlik (Yorgunluk, asabiyet); ve (v) Algılanan kontrol (Sınavın başarılı bir şekilde tamamlanacağına yönelik inanç). Danthony ve arkadaşları (2019) çalışmasında 19 madde ve beş faktörlü yapı toplam varyansın \% 63. 2'sini açıkladığını belirtmişlerdir. Ayrıca beş alt faktörün Cronbach Alfa değerleri .75 ile .89 arasında yer almaktadır. Geliştirilen ölçeğin geçerli ve güvenilir olduğu belirlenmiştir.

Alanyazın incelendiğinde beden eğitimi ve spor dersine yönelik sınav kaygısının Türk kültüründe ölçülmesi ve değerlendirilmesi önemlidir. Ne yazık ki Türk kültürüne uygun geçerli ve güvenilir bir beden eğitimi ve spor dersi sınav kaygısı ölçeği bulunmamaktadır. Bu çalışmanın amacı, Danthony ve arkadaşları (2019) tarafından geliştirilen beden eğitimi ve spor dersine yönelik sınav kaygısı ölçeğinin Türk kültürüne uyarlamasının gerçekleştirilmesidir. 


\section{Yöntem}

Bu bölümde araştırmaya dahil olan katıımcılar, veri toplama araçları, yapılan geçerlik ve güvenirlik analizlerine yönelik detaylar sunulmuştur. Çalışma öncesinde Karamanoğlu Mehmetbey Üniversitesi'nin etik kurulundan onay alınmıştır (Etik kurul no: E-95728670-044).

\section{Katılımcılar}

Çalışmaya 195 kız ve 164 erkek toplam 359 ortaokul öğrencisi gönüllü olarak katılmıştır. Katılımcıların yaş aralığı 11 ile 14 yaş ( $X=12.58 \pm 1.09$ ) olarak belirlenmiştir. Çalışmada yer alan ortaokul öğrencilerinin 58'i 5. sınıf (\% 20.45), 56 'sı 6. sınıf (\% 21.18), 78'i 7. sınıf (\% 28.47) ve 82'si 8. sınıf (\% 29.9) öğrencisidir. Öğrencilerin 135'i (\% 49.3) okul spor takımlarından birinde yer alırken 139'u (\% 50.7) okul takımlarında yer almamaktadır. Ayrıca katıımcıların 154'ü (\% 56.20) spor kulübünde lisanslı olarak spor yaparken 120'si (\% 43.80) lisanslı olarak spor yapmadığını belirtmişlerdir. Çalışmada yer alan 359 katıımcı, açımlayıcı faktör analizi (AFA), doğrulayıcı faktör analizi (DFA) ve test tekrar test yöntemi için tesadüfî yöntemle üç gruba ayrılmıştır. Tesadüfî olarak üç gruba ayrılan katıımcılardan elde edilen verilerin 74'ü AFA analizi, 200'ü DFA analizi ve 85'i test tekrar test yöntemi için kullanılmıştır. AFA için gerekli örneklem sayısı konusunda alanyazında farklı görüşler olsa da genel olarak 50 ve üzeri örneklem ile AFA analizinin yapılabileceği vurgulanmaktadır (Comrey, 1973; Gorsuch, 1974; lannucci vd., 2019; Mundfrom vd., 2005; Sapnas \& Zeller, 2002; Velicer \& Fava, 1998). Bu nedenle, 74 katılımcıdan elde edilen verinin AFA analizi için yeterli olduğu söylenebilir. DFA analizi için genel kabul görmüş gereklilik, örneklem sayısının AFA analizinde kullanılan sayıdan fazla olmasıdır (Brown, 2006; Tabachnick \& Fidell, 2013). Yong ve Pearce (2013), DFA analizi için örneklem sayıSI belirlemek için yaygın olarak önerilen yöntemlerden biri de madde sayısı x 10 yönteminin kullanılmasıdır. Bu çalışmanın DFA analizi için gerekli örneklem sayısı 19×10=190 olması beklenmektedir. DFA analizi için kullanılan 200 katılımcı gerekli sayıyı karşılamaktadır (Yong \& Pearce, 2013).

\section{Veri Toplama Araçları}

\section{Kişisel Bilgi Formu}

Çalışmada yer alan katııımcıların cinsiyet, yaş, sınıf, okul takımı ve spor kulübüne katııma değişkenleri açısından incelemek amacıyla araştırmacılar tarafından oluşturulmuştur.

\section{Beden Eğitimi Dersi Sınav Kaygısı Ölçeği}

Ölçek, Danthony, Mascret ve Cury (2019) tarafından ortaokul ve lise öğrencilerinin beden eğitimi dersine yönelik sınav kaygılarını belirlemek amacıyla geliştirilmiştir. Ölçeğin orijinal formu 19 maddeden oluşmakta ve yargılar 4 değerlendirme basamağına (1=Hiçbir zaman, 4=Her zaman) göre yapılmaktadır. Ölçek endişe (4 madde, örn:Başarısız olmaktan korkarım), kendi kendine odaklanma (3 madde, örn: Diğer öğrencilerin, performansımla dalga geçeceğinin farkındayım), bedensel belirtiler (4 madde, örn: Beden eğitimi sınavında, beden eğitimi derslerine göre daha çok titrerim), fiziksel gerginlik (4 madde, örn: Beden eğitimi sınavında, beden eğitimi derslerine göre kendimi daha fazla tedirgin hissederim) ve algılanan kontrol (4 madde, örn: lyi bir not almak için kendimi hazır hissederim) olmak üzere 5 alt boyuttan oluşmaktadır. Ölçeğin puanlaması alt boyutları oluşturan maddelerin toplanması ile gerçekleştirilmektedir. Ölçekten elde edilebilecek minimum puan 19 ve maksimum puan 76 olarak belirlenmiştir. Ölçekten elde edilen puan ne kadar düşük olursa katılımcının kaygı düzeyi o kadar düşük, ne kadar yüksek olursa katılımcının kaygı düzeyi o kadar yüksek olarak kabul edilmektedir.

\section{Ölçeğin Çeviri Aşaması}

Beden eğitimi ve spor dersi sınav kaygı ölçeğin çevirisi Brislin (1986) tarafından önerilen standart çeviri-geri çeviri yöntemi ile gerçekleştirilmiştir. Ölçeğin İngilizce formu spor bilimleri alanında iyi derecede Ingilizce bilgisine sahip üç akademisyene ve iki İngilizce dil bilim uzmanına Türkçe çeviri için gönderilmiştir. Elde edilen beş çeviride yer 
alan maddeler karşılaştırılarak tek bir form oluşturulmuştur. Oluşturulan bu form tekrar Türkçe'den İngilizce'ye farklı üç dil bilim uzmanı ve spor bilimleri alanında iyi derecede Ingilizce bilen bir akademisyene gönderilmiştir. Dört uzmandan gelen formlar orijinal form ile anlam ve biçim yönünden karşılaştırılmış ve ölçeğe son hali verilmiştir. Çeviri sürecinde orjinal forma bağlı kalınmış ve ölçeğe herhangi bir ifade eklenmemiştir. Ölçeğin anlam yönünden anlaşıırığı 12 ortaokul öğrencisi ile yüz yüze görüşme ile kontrol edilmiştir. Öğrenciler ölçeğin anlam ve biçim yönünden anlaşıır olduğunu belirtmişlerdir. Bu aşamadan sonra ölçeğin uygulamasına geçilmiştir.

\section{Veri Toplama Süreci}

Beden eğitimi ve spor dersi sınav kaygısı ölçeği, 2019-2020 güz eğitim öğretim yılında ortaokul öğrencilerine beden eğitimi ve spor ders saatinde sınıfta uygulanmıştır. Öğrencilerin 18 yaşından küçük olması nedeniyle veri toplama işleminden önce ailelerinden gönüllü katıım formu toplanmıştır. Ölçek dağıtıldıktan sonra çalışmanın amacı katılımcılara açıklanmıştır. Ölçeği doldurmaları için 15 dakika süre verilmiştir.

\section{Verilerin Analizi}

Beden eğitimi ve spor dersi sınav kaygısı ölçeğinin analiz işlemleri için aritmetik ortalama, standart sapma, çarpıklık ve basıklık değerlerini içeren betimsel analizler kontrol edilmiştir. Ölçeğin yapı geçerliği AFA ve DFA ile kontrol edilmiştir. AFA analizi için SPSS 24.0 ve DFA analizi için AMOS paket programları kullanılmıştır. AFA analiz işlemlerinde maddelerin faktör dağılımları ve yapısını belirlemede bulguların çoklu normallik dağılımı göstermesi nedeniyle maksimum olasılık yöntemi tercih edilmiştir (Fabrigar vd., 1999).Ölçeğin güvenirliği için ise Cronbach Alfa katsayısı ve test tekrar test yöntemleri kullanılmıştır.

\section{Bulgular}

\section{Ölçeğin Geçerlik Analizleri}

\section{Sayıltılar}

AFA ve DFA analizlerinden önce toplanan verinin sayıltıları karşılayıp karşılamadığı kontrol edilmiştir. Ilkk olarak kayıp veri olup olmadığı incelenmiş ve kayıp veri olmadığı belirlenmiştir. İkinci olarak çok değişkenli uç değer olup olmadığı, Leverage uzaklık değerleri kontrol edilmiş ve uç değerlerin olmadığı tespit edilmiştir. Üçüncü sayıtlı olarak maddeler arası çoklu bağlantı kontrol edilmiştir. Madde puanları arası korelasyon değeri .80 ve üzeri olması çoklu bağlantı sorununa işaret etmektedir. Yapılan kontrollerde maddeler arası korelasyon değerlerinin .80'nin altında olduğu belirlenmiştir. Ayrıca toplanan verilerin faktör analizine uygunluğu için Kaiser-Meyer Olkin (KMO) ve Bartlett testleri kontrol edilmiştir (Tablo 1). KMO değerinin .70'den yüksek ve Bartlett testi değerinin ise anlamlı olması ( $p<.05)$ gerekmektedir (Tavşancıl, 2005). Elde edilen bulgular KMO değerinin .90 ile beklenen değerin üzerinde ve Bartlett test değerinin anlamlı olduğu belirlenmiştir. Faktör analizi için gerekli sayıltıların tamamı sağlanmıştır.

Tablo 1. Kaiser-Meyer-Olkin ve Bartlett Test Bulguları

\begin{tabular}{lcc}
\hline Test & Değer \\
\hline Kaiser-Meyer-OlkinMeasure of SamplingAdequacy. & .90 \\
\hline Bartlett's Test of & Approx. Chi-Square & 6941.67 \\
Sphericity & df & 171 \\
& Sig. & .00 \\
\cline { 2 - 3 }
\end{tabular}




\section{Açımlayıcı Faktör Analizi (AFA)}

Ölçeğin Türkçe uyarlama formunun yapı geçerliğini test etmek için AFA analizi kullanılmıştır. Ayrıca faktörleştirme yöntemlerinden maksimum olabilirlik yöntemi ve döndürme yöntemi olarak da eğik döndürme yöntemlerinden doğrudan (direct) oblimin tercih edilmiştir. Tercih edilen yöntemler faktör yapısı ve döndürme işlemleri açısından diğer yöntemlere göre daha güvenilirdir (Tabachnick \& Fidell, 2013). Ölçeğin orijinal formunda yer alan 19 madde ile AFA analizine başlanmıştır. Analiz sonucunda öz değeri 1'in üzerinde olan ve toplam varyansın \% 67.18'ini açıklayan toplam 5 faktör ortaya çıkmıştır. Sonrasında yapılan eğik döndürme işlemi yine 5 faktörlü yapı ortaya çıkarmıştır. Ayrıca faktör belirlemede her faktörün toplam varyansa katkısının \% 5 ve üzeri olması beklenmektedir (Kalaycı,2014). Öz değerler tablosu incelendiğinde 5 faktörün tamamının \% 5 ve üzeri olduğu belirlenmiştir. Ortaya çıkan 5 faktörlü yapı ölçeğin orijinal faktör yapısı ile uyumludur. Ayrıca açıklanan varyans yüzdesinin yeterli olduğu belirlenmiştir (Scherer vd., 1988; Yaşlığlu, 2017). Maddelerin faktör yükleri incelendiğinde 19 maddenin tamamının beklenen ayırt edicilik düzeyi olan .30 ve üzeri değere sahip oldukları belirlenmiştir (Büyüköztürk, 2007) . Faktörlerin toplam açıklanan varyans yüzdesi, öz değerleri ve madde yükleri Tablo z'de verilmiştir.

Tablo 2. Desen Matriksi, Madde Yükleri, Toplam Açıklanan Varyans ve Öz Değerler Tablosu

\begin{tabular}{|c|c|c|c|c|c|}
\hline & 1 & 2 & 3 & 4 & 5 \\
\hline S2 & .86 & & & & \\
\hline $\mathrm{S}_{1}$ & .47 & & & & \\
\hline S3 & .36 & & & & \\
\hline $\mathrm{S}_{4}$ & 32 & & & & \\
\hline $\mathrm{S}_{5}$ & & .74 & & & \\
\hline S7 & & .73 & & & \\
\hline s6 & & .70 & & & \\
\hline $\mathrm{S}_{10}$ & & & .72 & & \\
\hline S9 & & & .70 & & \\
\hline $\mathrm{S}_{11}$ & & & .43 & & \\
\hline S8 & & & .42 & & \\
\hline $\mathrm{S}_{14}$ & & & & .95 & \\
\hline $\mathrm{S}_{12}$ & & & & .80 & \\
\hline $\mathrm{S}_{13}$ & & & & .67 & \\
\hline $\mathrm{S}_{15}$ & & & & .30 & \\
\hline $\mathrm{S}_{19}$ & & & & & .88 \\
\hline S17 & & & & & .87 \\
\hline $\mathrm{S}_{16}$ & & & & & .83 \\
\hline $\mathrm{S}_{18}$ & & & & & .72 \\
\hline $\begin{array}{c}\text { Öz Değer } \\
\text { (Toplam 13.47) } \\
\end{array}$ & 6.46 & 2.77 & 1.88 & 1.32 & 1.04 \\
\hline $\begin{array}{l}\text { Açılalanan Varyans (\%) } \\
\text { (Toplam \% 67.18) }\end{array}$ & 33.98 & 14.24 & 8.23 & 5.59 & 5.14 \\
\hline
\end{tabular}


Tablo 3. Faktörlerin Beden Eğitimi Dersi Sınav Kaygısı Ölçeği Toplam Puanları ile Korelasyonları

\begin{tabular}{|c|c|c|c|c|c|}
\hline & $\begin{array}{c}\text { Kendi } \\
\text { kendine } \\
\text { odaklanma }\end{array}$ & $\begin{array}{l}\text { Bedensel } \\
\text { belirtiler }\end{array}$ & $\begin{array}{l}\text { Fiziksel } \\
\text { gerginlik }\end{array}$ & $\begin{array}{l}\text { Algilanan } \\
\text { kontrol }\end{array}$ & Toplam kaygı \\
\hline Endişe & $.51^{*}$ & $.49^{*}$ & $.50^{*}$ & $-.33^{* *}$ & $.73^{*}$ \\
\hline $\begin{array}{l}\text { Kendi kendine } \\
\text { odaklanma }\end{array}$ & & $.35^{* *}$ & $.40^{*}$ & $-.30^{*}$ & $.63^{*}$ \\
\hline Bedensel belirtiler & & & $.70^{*}$ & $-.17^{* *}$ & $.81^{* *}$ \\
\hline Fiziksel gerginlik & & & & $-.26^{* *}$ & $.80^{*}$ \\
\hline Algılanan kontrol & & & & & $-.87^{* *}$ \\
\hline
\end{tabular}
${ }^{* *} \mathrm{p}<.01$

Tablo 3. incelendiğinde beden eğitimi ve spor dersi sınav kaygısı ölçeğinin faktörleri ile toplam kaygı puanları arasında yüksek düzeyde korelasyon olduğu tespit edilmiştir (Büyüköztürk, 2007).

\section{Doğrulayıcı Faktör Analizi (DFA)}

AFA sonucunda elde edilen beş faktör ve 19 maddeden oluşan yapı DFA analizi ile kontrol edilmiştir. Oluşan modelin uyumluluğunun sınandığı DFA için farklı uyum indeksi değerleri kullanılmaktadır. Alan yazındaki çalışmaların çoğunluğunda kullanılan Ki kare uyum testi (Chi-Square Goodness), RMSEA (Root Mean Square Error of Approximation), GFI (Goodness of Fit Index). NFI (Normed Fit Index), RFI (Relative Fit Index), CFI (Comparative Fit Index). AGFI (Adjusted Goodness of Fit Index) ve IFI (Incremental Fit Index) uyum indeksleri bu çalışma için kontrol edilmiştir.Değerlerin kabul edilebilir ve mükemmel uyum indeksi değerleri olduğu belirlenmiştir (Aytaç \& Öngen, 2012; Bayram, 2010; Meydan \& Şeşen, 2011; Şimşek, 2007). Ölçeğin DFA bulguları Tablo 4 'te verilmiştir.

Tablo 4. Beden Eğitimi Dersi Sınav Kaygısı Ölçeği Uyum Değerleri

\begin{tabular}{cccc}
\hline Model Uyum İndeks & Mükemmel Aralık & Kabul Edilebilir Aralık & Ölçek Değeri \\
\hline X2/df & $0<\mathrm{X} 2 / \mathrm{df}<2$ & $2<\mathrm{X} 2 / \mathrm{df}<5$ & 3.06 \\
$\mathrm{RMSEA}$ & $.00<\mathrm{RMSEA}<.05$ & $.05<\mathrm{RMSEA}<.08$ & .05 \\
$\mathrm{GFI}$ & $.95<\mathrm{CFI}<1.00$ & $.90<\mathrm{CF}<<.95$ & .94 \\
$\mathrm{CFI}$ & $.95<\mathrm{CFI}<1.00$ & $.90<\mathrm{CF}<.95$ & .96 \\
$\mathrm{NFI}$ & $.95<\mathrm{CFI}<1.00$ & $.90<\mathrm{CFI} .95$ & .94 \\
$\mathrm{IFI}$ & $.95<\mathrm{CFI}<1.00$ & $.90<\mathrm{CF}<.95$ & .93 \\
$\mathrm{AGFI}$ & $.95<\mathrm{AGF|}<1.00$ & $.50<\mathrm{AGF|}<.95$ & .93 \\
\hline
\end{tabular}

Tablo 4.incelendiğinde beden eğitimi dersi sınav kaygısı ölçeğinin DFA bulgularına yönelik tüm parametrelerinin beklenen uyum indeksi değerlerine sahip olduğu belirlenmiştir. Ölçeğin 5 alt boyut ve 19 soruluk maddelik yapısının uygun olduğu tespit edilmiştir (df=142, $X^{2}=434,269$; RMSEA=.05, GFI=.94, CFI=.96, NFI=94, IFI=.93, AGFI=.93). 


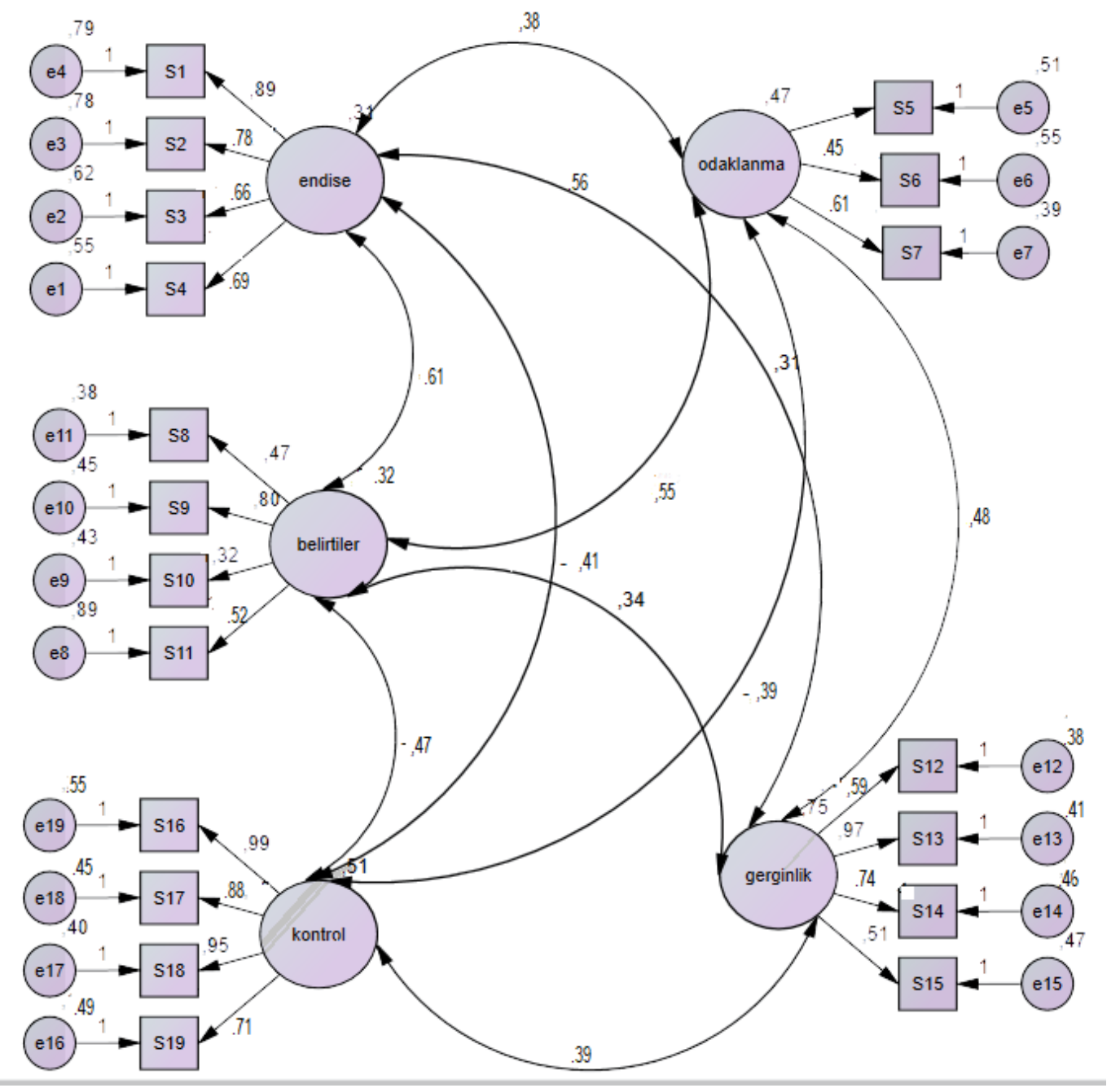

Şekil 1. Beden Eğitimi Dersi Sınav Kaygısı Ölçeği Standardize Edilmiş Değerleri

Şekil 1'de yer alan standardize edilmiş değerlerin 1.0 değerinin altında olması gerekmektedir (Aytaç ve Öngen, 2012). Diyagram incelendiğinde tüm değerler beklenen 1.0 değerinin altında olduğu görülmektedir.

\section{Ölçeğin Güvenirlik Analizleri}

Ölçeğin güvenirliğini belirlemek için iç tutarlık katsayısı ve test tekrar test yöntemleri kullanılmıştır. l̇ç tutarlık analizi için Cronbach Alfa değeri kontrol edilmiştir. Alfa katsayısı, 0.40 ile 0.00 arasında ise olan değerler ölçeğin güvenilir olmadığını, 0.60 ile 0.40 düşük ise güvenirliliğe sahip olduğuna, 0.80 ile 0.60 arasında oldukça güvenilir olduğunu ve 0.80 ile 1.00 arasında ise ölçeğin yüksek güvenirliliğe sahip olduğunu belirtmektedir (Alpar, 2006).

Ölçeğin güvenirliği belirlemede ikinci yöntem olarak test tekrar test yöntemi kullanılmıştır. Bu yöntem ile ölçeğe verilen cevapların zaman içinde değişip değişmediği kontrol edilmektedir. Tavşancıl (2014), değerin .70 ve üzeri olması gerektiğini belirtmektedir. Bu yöntem için 85 öğrenciden dört hafta ara ile iki kez veri toplanmıştır. 
Tablo 5. Beden Eğitimi Dersi Sınav Kaygısı Ölçeğin Iç Tutarlık ve Test Tekrar Test Yöntemleri ile Güvenirlik Hesaplanması

İç Tutarlık Test Tekrar Test

\begin{tabular}{lll}
\hline Endişe & .68 & .81 \\
Kendi kendine odaklanma & .77 & .84 \\
Bedensel belirtiler & .75 & .82 \\
Fiziksel gerginlik & .86 & .86 \\
Algılanan kontrol & .89 & .79 \\
Toplam & .81 & .88 \\
\hline
\end{tabular}

Ölçeğin güvenirliği için kullanılan iç tutarlık ve test tekrar test yöntemlerinden elde edilen bulgular ölçeğin tamamının ve alt boyutlarının belirlenen ölçütlerin üstünde olduğu bulunmuştur.

Tablo 6. Madde-Toplam Korelasyon ve Madde Çıkarılırsa Cronbach Alfa Değeri Tablosu

\begin{tabular}{lcc}
\hline & Madde-Toplam Test Korelasyonu & $\begin{array}{c}\text { Madde Çıarılırsa Cronbach Alfa } \\
\text { Değeri }\end{array}$ \\
\hline S1 & .39 & .80 \\
S2 & .41 & .79 \\
S3 & .52 & .79 \\
S4 & .37 & .80 \\
S5 & .39 & .80 \\
S6 & .44 & .79 \\
S7 & .45 & .79 \\
S8 & .59 & .78 \\
S9 & .62 & .78 \\
S10 & .55 & .79 \\
S11 & .39 & .80 \\
S12 & .64 & .78 \\
S13 & .66 & .78 \\
S14 & .65 & .78 \\
S15 & .46 & .79 \\
S16 & .48 & .81 \\
S17 & .42 & .81 \\
S18 & .55 & .81 \\
S19 & .53 & .81 \\
\hline
\end{tabular}

Tablo 6 incelendiğinde madde-toplam test korelasyon değerlerinin tamamının pozitif ve 30 değerinin üzerinde olduğu görülmektedir. Ayrıca ölçeğin herhangi bir maddesi çıkarılırsa ölçeğin Cronbach Alfa değeri toplam değer olan 81 den daha yüksek bir değer sağlamayacağı için herhangi bir maddenin çıkarılmasına gerek olmadığı belirlenmiştir. 


\section{Tartışma}

Bu çalışma Danthony ve arkadaşları (2019) tarafından geliştirilen "Beden Eğitimi ve Spor Dersi Sınav Kaygısı" ölçeğinin Türk kültürüne uyarlamasının yapılması amacıyla gerçekleştirilmiştir. Ölçeğin faktör yapısını belirlemek için AFA ve DFA kullanılmıştır. Elde edilen bulgular, Danthony ve arkadaşlarının (2019) geliştirdiği orijinal ölçekte yer alan 19 madde ve 5 faktörlü yapının bu çalışmada da ortaya çıktığı görülmektedir.

AFA sürecinde tercih edilen maksimum olabilirlik yöntemi ve döndürme yöntemi olarak da eğik döndürme yöntemlerinden doğrudan (direct) oblimin kullanılması ölçeğin madde ve faktör yapısının geçerliği açısından önemlidir (Myung, 2003; Spanos, 1999). Ölçeğin varyans açıklama oranı ne kadar yüksek olursa o kavramın ya da yapının o denli iyi ölçüldüğüne işaret etmektedir (Büyüköztürk, 2007). Alanyazında faktör analizi için gerekli varyans açıklama oranı hakkında farklı yorumlar olsa da genel olarak \% 50 ve üzeri açıklanan varyans yeterli olarak kabul edilmektedir(Merenda, 1997; Peterson, 2000). Çalışmamızda açıklanan toplam varyans \% 67.18 ile oldukça yeterli bulunmuştur. Ölçeğin madde-toplam korelasyon değerlerinin yorumlanmasında her madde yükünün .30 ve üzeri olması kriteri esas alınmıştır (Büyüköztürk, 2007). Çalışmamız bulguları tüm madde yüklerinin .30 ve üzeri kriterini sağladığını göstermektedir.

AFA analizi sonrasında oluşan faktör yapısının Türk örneklem grubundan toplanan veriler ile ne derecede uyum gösterdiğini belirlemek amacıyla DFA yapılmıştır. DFA analizi sonucunda modelin RMSEA değeri .05, GFI değeri .94, CFI değeri .96, NFI değeri .94, IFI değeri .93 ve AGFI değeri .93 olarak belirlenmiştir. Elde edilen bulgular modelin uyum indekslerinin ve parametrelerinin tamamının beklenen düzeyin üzerinde olduğunu göstermektedir (Schermelleh-Engel \& Moosbrugger, 2003). Ölçekten elde edilen uyum indeks değerleri, Danthony ve arkadaşlarının (2019) ölçeğin geliştirilme çalışmasında 281 öğrenci üzerine elde ettikleri uyum indeks değerleri ile paralellik göstermektedir.

Türk kültürüne uyarlaması yapılan beden eğitimi ve spor dersi sınav kaygısı ölçeğinin güvenirliğini belirlemek için Cronbach alfa iç tutarlıık katsayısı ve test tekrar test yöntemleri kullanılmıştır. Ölçeğin alt boyutlarındaki iç tutarlıık değerleri Danthony ve arkadaşlarının (2019) çalışmasında elde edilen bulgular ile benzerlik göstermektedir. Ölçeğin orijinal çalışmasında kullanılmamış olsa da test tekrar test güvenirlik yönteminden elde edilen bulgular ölçeğin güvenilir olduğunu işaret etmektedir.

\section{Sonuç}

Öğrencilerin beden eğitimi ve spor dersine yönelik sınav kaygılarını ölçmek amacıyla geliştirilen Beden Eğitimi ve Spor Dersi Sınav Kaygısı Ölçeği'nin Türkçe uyarlamasının geçerlik ve güvenirliğini test etmek amacıyla gerçekleştirilen bu çalışma sonucunda; ölçeğin, öğrencilerin beden eğitimi ve spor dersine yönelik sınav kaygılarını ölçmek için kullanılabilir bir ölçme aracı olduğu söylenebilir. Türk kültürüne uyarlanan ölçeğin, beden eğitimi ve spor dersinde sınav olan öğrencilerin kaygı düzeylerini ölçme konusunda alanyazına önemli katkı sağlaması beklenmektedir. Ölçekten elde edilen sonuçlar bu çalışmada yer alan örneklem grubu için yeterli olsa da farklı örneklem ve yaş gruplarında yapılacak olan çalışmalara gereksinim olduğu düşünülmektedir.

\section{Kaynakça}

Aytaç, M.,\& Öngen, B. (2012). Doğrulayıcı faktör analizi ile yeni çevresel paradigma ölçeğinin yapı geçerliliğinin incelenmesi. Istatistikçiler Dergisi: Istatistik ve Aktüerya, 5(1), 14-22.

Barkoukis, V., Rodafinos, A., Koidou, E., \& Tsorbatzoudis, H. (2012). Development of a scale measuring trait anxiety in physical education. Measurement in Physical Education and ExerciseScience, 16(4): 237-253. https://doi.org/10.1080/1091367X.2012.716724 
Barkoukis, V., Tsorbatzoudis, H., Grouios, G., \& Rodafinos, A. (2005). The development of a physical education state anxiety scale: A preliminary study. Perceptual and Motor Skills, 100(1), 118-128. https://doi.org/10.2466/pms.100.1.118-128

Bayram, N. (2010). Yapısal Eşitlik Modellemesine Giriş AMOS Uygulamaları. İstanbul: Ezgi Kitabevi.

Benson, J., \& El-Zahhar, N. (1994). Further refinement and validation of the Revised Test Anxiety Scale with cross-validation. Structural Equation Modelling, 1(3), 203-221. https://doi.org/10.1080/10705519409539975

Brislin, R. W. (1986). A culture general assimilator: Preparation for various types of sojourns. International Journal of Intercultural Relations, 10(2), 215-234.https://doi.org/10.1016/0147-1767(86)90007-6

Brown, T.A. (2006). Confirmatory Factor Analysis For Applied Research. New York: The Guilford Press.

Büyüköztürk, Ş. (2007). Spss veri analizi el kitabı. Ankara: PegemA Yayıncılık.

Chapell, M. S., Blanding, Z. B., Silverstein, M. E., Takahashi, M., Newman, B., Gubi, A. \& McCann, N. (2005). Test anxiety and academic performance in undergraduate and graduate students. Journal of Educational Psychology, 97(2), 268-274. https://doi.org/10.1037/0022-0663.97.2.268

Comrey, A. L., Backer, T. E., \& Glaser, E. M. (1973). A Source Book For Mental Health Measures. Los Angeles: Human Interaction Research Institute.

Coşkun, Y., \& Akkaş, G. (2009). Engelli çocuğu olan annelerin sürekli kaygı düzeyleri ile sosyal destek algıları arasındaki ilişki. Ahi Evran Üniversitesi Kırşehir Eğitim Fakültesi Dergisi.10(1), 213-227.

Cüceloğlu, D. (1994). İçimizdeki çocuk; Yaşamımıza yön veren güçlü varlık. Istanbul: Remzi Kitabevi.

Danthony, S., Mascret, N., \& Cury, F. (2019). Development and validation of a scale assessing test anxiety in physical education. Journal of Teaching in Physical Education, 38(4), 357-366. https://doi.org/10.1123/jtpe.2018-0282

Danthony, S., Mascret, N., \& Cury, F. (2020). Test anxiety in physical education: The predictive role of gender, age, and implicit theories of athletic ability. European Physical Education Review, 26(1), 128-143. https://doi.org/10.1177/1356336X19839408

Eisinga, R., Te Grotenhuis, M., \& Pelzer, B. (2013). There liability of a two-item scale: Pearson, Cronbach, or Spearman-Brown. International journal of public health, 58(4), 637-642. https://doi.org/10.1007/s00038-012-0416-3

Fabrigar, L. R.,Wegener, D. T. MacCallum, R. C. \& Strahan, E. J. (1999). Evaluating the use of exploratory factor analysis in psychological research. Psychological methods, 4(3), 272. https://doi.org/10.1037/1082-989X.4.3.272

Gençdoğan, B. (2006). Lise öğrencilerinin sınav kaygısı ile boyun eğicilik düzeyleri ve sosyal destek algısı arasındaki ilişkiler. Atatürk Üniversitesi Sosyal Bilimler Enstitüsü Dergisi, 7(1), 153-164.

Gorsuch, R. L. (1974). Factor analysis. Philadelphia: Saunders.

Gündoğdu, M. (1994). The relationship between help leşs explanatory style, test anxiety, and academic achievement among sixth grade basic education students. Master's Thesis, Middle East Technical University. The Graduate School of Social Science, Ankara.

Lannucci, C., MacPhail, A., \& R. Richards, K. A. (2019). Development and initial validation of the Teaching Multiple School Subjects Role Conflict Scale (TMSS-RCS). European Physical Education Review, 25(4), $1017-1035$ 
Kalaycı, Ş. (2014). SPSS Uygulamalı çok değişkenli istatistik teknikleri. (6. Baskı) Ankara: Asil Yayın.

Merenda, P. F. (1997). A guide to the proper use of factor analysis in the conduct and reporting of research: Pitfalls to Avoid. Measurement and Evaluation in counseling and Development, 30(3), 156-164. https://doi.org/10.1080/07481756.1997.12068936

Meydan, C. H., \& Şeşen, H. (2011). Yapısal eşitlik modellemesi ve AMOS uygulamaları. Ankara: Detay Yayıncılık.

Mundfrom, D. J.Shaw, D. G., \& Ke, T. L. (2005). Minimum sample size recommendations for conducting factor analysis. International Journal of Testing , 5(2), 159-168. https://doi.org/10.1207/s15327574ijt0502_4

Myung, I. J. (2003). Tutorial on maximum likelihood estimation. Journal of mathematical Psychology, 47(1), 90-100. https://doi.org/10.1016/S0022-2496(02)00028-7

Öner, N., \& Le Compte, A. (1983). Durumluk-Sürekli Kaygı El Kitabı. İstanbul: Boğaziçi Üniversitesi Yayınları.

Özgür, T. (2018). Futbol okullarında eğitim alan gençlerin lisanslı futbolcu olabilmeleriyle ilgili kaygı düzeylerinin belirlenmesi. Yayımlanmamış Doktora Tezi, İstanbul Gelişim Üniversitesi, Sağlık Bilimleri Enstitüsü, İstanbul.

Peterson, R. A. (2000). A meta-analysis of variance accounted for and factor loadings in exploratory factor analysis. Marketing letters, 11(3), 261-275. https://doi.org/10.1023/A:1008191211004

Putwain, D. W., Woods, K., \& Symes. W. (2010) Personal and situational predictors of test anxiety of students in post-compulsory education. British Journal of Educational Psychology, 80, 137-160. https://doi.org/10.1348/000709909X466082

Sapnas, K. G., \& Zellar, R. A. (2002). Minimizing sample size when using exploratory factor analysis for measurement. Journal of nursing measurement, 10(2), 135-154. htps://doi.org/10.1891/jnum.10.2.135.52552

Scherer, R. F., Luther, D. C., Wiebe, F. A., \& Adams, J. S. (1988). Dimensionality of coping: Factor stability using the ways of coping questionnaire. Psychological Reports, 62(3), 763-770. https://doi.org/10.2466/pro.1988.62.3.763

Schermelleh-Engel K., \& Moosbrugger H. (2003). Evaluating the fit of structural equation models: Tests of significance and descriptive goodness-of-fit measures. Methods of Psychological Research Online,8(2), 23-74.

Spanos, A. (1999). Probability Theory and statistical inference. Cambridge, UK: Cambridge UniversityPress.

Spielberger, C. D. \& Vag, R. (1995). Test anxiety: Theory assessment and treatment. Taylor and Francis Publishers.

Spielberger, C. D. (1980). Test anxiety inventory: Preliminary professional manual, Palo Alto, CA: Consulting Psychologist Press. https://doi.org/10.1002/9780470479216.corpsy0985

Şimşek, Ö. F. (2007). Yapısal eşitlik modellemesine giriş: Temel ilkeler ve LISREL uygulamaları. Ankara: Ekinoks Yayınları.

Tabachnick, B. G.,\& Fidell, L. S. (2013). Using Multivariate Statistics (6th ed.), Boston: Allyn and Bacon.

Tavşancıl, E. (2005). Tutumların ölçülmesi ve SPSS ile veri analizi. Ankara: Nobel Yayın Dağııım. 
Tavşancıl, E. (2014).Tutumların Ölçülmesi ve SPSS ile Veri Analizi. (5. Baskı) Ankara: Nobel Yayınevi

Velicer, W. F., \& Fava, J. L. (1998). Affects of variable and subject sampling on factor pattern recovery. Psychological methods, 3(2), 231. https://doi.org/10.1037/1082-989X.3.2.231

Walling, M. D.,\& Duda, J. L. (1995). Goals and their associations with beliefs about success in and perceptions of the purposes of physical education. Journal of Teaching in PhysicalEducation, 14(12), 140-156. https://doi.org/10.1123/jtpe.14.2.140

Yaşlıoğlu, M. M. (2017). Sosyal bilimlerde faktör analizi ve geçerlilik: Keşfedici ve doğrulayıcı faktör analizlerinin kullanılması. İstanbul Üniversitesi İsletme Fakültesi Dergisi, 46, 74-85.

Yavuzer, H. (2004). Ana- Baba ve Çocuk. İstanbul: Remzi Kitapevi.

Yong, A. G., \& Pearce, S. (2013). A beginner's guide to factor analysis: Focusing on exploratory factor analysis. Tutorials in quantitative methods for psychology, 9(2), 79-94. https://doi.org/10.20982/tqmp.09.2.p079

Zeidner, M. (1998). Test Anxiety: The State of the Art.New York: Plenum Press.

Zeidner, M. (2007). Test anxiety in educational contexts: Concepts, findings, and future directions. In Emotion in education (pp. 165-184). Academic Press. https://doi.org/10.1016/B978-012372545-5/50011-3

Zeidner, M., \& Matthews, G. (2005). Evaluation Anxiety. In A. J. Elliot \& C. S. Dweck (Eds.), Handbook of competence and motivation (141-163). New York: Guilford Press. 